\title{
Hydrogen absorption study of high-energy reactive ball milled Mg composites with palladium additives
}

M. Williams, J.M. Sibanyoni, M. Lototskyy and B.G. Pollet

\begin{abstract}
Hydrogenation behaviour, structure, morphology and dehydrogenation/rehydrogenation performances of $\mathrm{Mg}-\mathrm{Pd}$ nanocomposites prepared by high-energy reactive ball milling in $\mathrm{H}_{2}$ (HRBM) of $\mathrm{Mg}$ in the presence of amorphous and crystalline Pd black (0.1-5 wt.\%) were studied. Improvements of hydrogenation kinetics during HRBM were observed only for the materials prepared using crystalline Pd black. The obtained nanocomposites were characterised by modest improvements in their dehydrogenation and re-hydrogenation performances associated with the formation of $\mathrm{Mg}-\mathrm{Pd}$ intermetallides.
\end{abstract}

\section{Introduction}

Over the last two decades, numerous studies were undertaken in an effort to enhance $\mathrm{Mg}$ hydrogenation rates [1]. One of the most promising approaches was found to be mechanical milling (MM). The products of MM often exhibit unusual physical and chemical properties and enhanced reactivity, in particular with respect to hydrogen. The enhancements are especially pronounced for Mg-based materials where nanostructuring and surface modification result in dramatic improvements in the hydrogenation kinetics [2]. Additional improvement of the hydrogenation performances of $\mathrm{Mg}$ was observed upon introduction of catalytic additives, including transition metals, alloys and intermetallic compounds [3-9]. High energy reactive ball milling (HRBM) of $\mathrm{Mg}$ with catalytic additives in $\mathrm{H}_{2}$ has been proven to be the most efficient way to further improve the re-hydrogenation process $[6,7]$.

The catalytic effect of the metallic additives, most probably, relates to facilitation of the reactions of hydrogen transfer, including dissociative chemisorption and associative desorption of $\mathrm{H}_{2}$ molecules. One of the most efficient catalysts for these processes is palladium. Indeed, Pd-coated magnesium thin films were shown to be characterised by significantly improved kinetics of hydrogenation of $\mathrm{Mg}$ and dehydrogenation of the formed $\mathrm{MgH}_{2}$ [10-12]. At the same time, $\mathrm{HRBM}$ of $\mathrm{Mg}$ with $\mathrm{Pd}$ additive was shown to inhibit both hydrogenation and re-hydrogenation of $\mathrm{Mg}$ [13]. 
In this work we report about investigation of HRBM of Mg in the presence of a Pd black catalyst.

\section{Experimental}

Mg powder (-20 ... +100 mesh, 99.8\%; metal basis) was purchased from AlfaAesar. Pd black was prepared as follows. $\mathrm{PdCl}_{2} \cdot \mathrm{xH}_{2} \mathrm{O}(1 . \mathrm{Og})$ and concentrated $\mathrm{HCl}$ $(1 \mathrm{~mL})$ were dissolved in $100 \mathrm{~mL}$ of the de-ionised water. The solution was heated to $\sim 70{ }^{\circ} \mathrm{C}$ under vigorous stirring, followed by drop-wise addition of $3-4 \mathrm{~mL}$ of $\mathrm{N}_{2} \mathrm{H}_{4} \cdot \mathrm{xH}_{2} \mathrm{O}$, or $10 \mathrm{~g} / \mathrm{L}$ aqueous solution of $\mathrm{NaH}_{2} \mathrm{PO}_{2}$, which resulted in the formation of black precipitates. The reduction of Pd black was driven to completion with an excess of $\mathrm{N}_{2} \mathrm{H}_{4}$, or $\mathrm{NaH}_{2} \mathrm{PO}_{2}$. The deposit was collected by gravity filtration, washed with copious quantities of water, and dried at $120{ }^{\circ} \mathrm{C}$ for $12 \mathrm{~h}$ in air. XRD studies confirmed that Pd black obtained using $\mathrm{N}_{2} \mathrm{H}_{4} \cdot \mathrm{xH}_{2} \mathrm{O}$ as a reducing agent was crystalline, and that prepared by reduction with $\mathrm{NaH}_{2} \mathrm{PO}_{2}$ was amorphous, in accordance with literature data and our earlier observations [14].

The Mg-xPd mixtures ( $\mathrm{x}=0.1,0.5,1,2$ and 5 wt.\%) containing crystalline (reduced with $\mathrm{N}_{2} \mathrm{H}_{4}$ ) and amorphous (reduced with $\mathrm{NaH}_{2} \mathrm{PO}_{2}$ ) Pd black, were ball milled in $\mathrm{H}_{2}$ using a Retsch PM 100 ball mill and $220 \mathrm{~mL}$ hardened steel vial with pressuretemperature monitoring system (Evico Magnetics $\mathrm{GmbH}$ ). The milling was performed with a ball-to-powder-ratio of 40:1 (82 steel balls, $10 \mathrm{~mm}$ in diameter) at $500 \mathrm{rpm}$, for $6 \mathrm{~h}$ in total. Prior to the milling, the vial was evacuated followed by filling with $\mathrm{H}_{2}$ gas ( $\mathrm{P} \sim 30$ bar) supplied from a metal hydride hydrogen storage and supply unit on the basis of $\mathrm{AB}_{5}$-type alloy. The hydrogen pressure in the vial was kept above 20 bar by refilling each time $(\mathrm{P} \sim 30$ bar) when the pressure dropped below this value. When the vial temperature approached $70{ }^{\circ} \mathrm{C}$, the milling was stopped and resumed again after cooling the vial to room temperature. The amount of hydrogen absorbed in the sample was calculated starting from actual pressuretemperature values (with the correction to hydrogen compression factor) and plotted versus milling time.

A High Resolution Transmission Electron Microscope (HRTEM), FEI Tecnai 30, operating at $120 \mathrm{kV}$ was used to analyze the morphology of the as-prepared and rehydrogenated samples. The sample holder was cooled to $\sim 90 \mathrm{~K}$.

XRD studies were performed using Bruker AXS D8 Advance diffractometer with Cu Ka radiation $\left(\mathrm{k}_{1}=1.5406 \AA, \mathrm{k}_{2}=1.5444 \AA, \mathrm{k}_{2} / \mathrm{k}_{1}=0.5\right)$. The Bragg angle range was $2 \mathrm{~h}=20-90^{\circ}$, and scan rate was $1.2^{\circ} / \mathrm{min}$ with a step size of $0.02^{\circ}$. The collected XRD data were refined by Rietveld whole-profile refinement using GSAS software [15], where the peak shapes were described using the Thompson-Cox-Hastings pseudoVoight-type function (CW profile function 2). A standard a- $\mathrm{Al}_{2} \mathrm{O}_{3}$ sample was used for the determination of the instrumental contribution into peak profile parameters. 
Table 1

Characteristics of HRBM Mg and Mg-Pd composites prepared using crystalline Pd black.

\begin{tabular}{|c|c|c|c|c|c|}
\hline \multirow[t]{2}{*}{ Composite } & \multicolumn{2}{|c|}{ Maximum H capacity (wt.\% H) } & \multicolumn{2}{|c|}{ Time of $90 \%$ hydrogenation (min) } & \multirow[t]{2}{*}{ TDS peak ${ }^{\mathrm{b}}\left({ }^{\circ} \mathrm{C}\right.$} \\
\hline & HRBM & Re-hydrogenation ${ }^{a}$ & HRBM & Re-hydrogenation ${ }^{a}$ & \\
\hline $\mathrm{Mg}$ & 7.69 & 3.41 & 221 & 110 & 375 \\
\hline $\mathrm{Mg}-0.1 \mathrm{Pd}$ & 6.42 & - & 460 & - & - \\
\hline $\mathrm{Mg}-0.5 \mathrm{Pd}$ & 7.10 & 5.13 & 113 & 26 & 350 \\
\hline $\mathrm{Mg}-2 \mathrm{Pd}$ & 7.65 & 4.88 & 218 & 38 & 341 \\
\hline $\mathrm{Mg}-5 \mathrm{Pd}$ & 7.59 & 5.56 & 162 & 52 & 345 \\
\hline
\end{tabular}

a 15 bar $\mathrm{H}_{2} / 230^{\circ} \mathrm{C}$, after TDS of the re-hydrogenated material.

${ }^{b}$ For the re-hydrogenated sample.
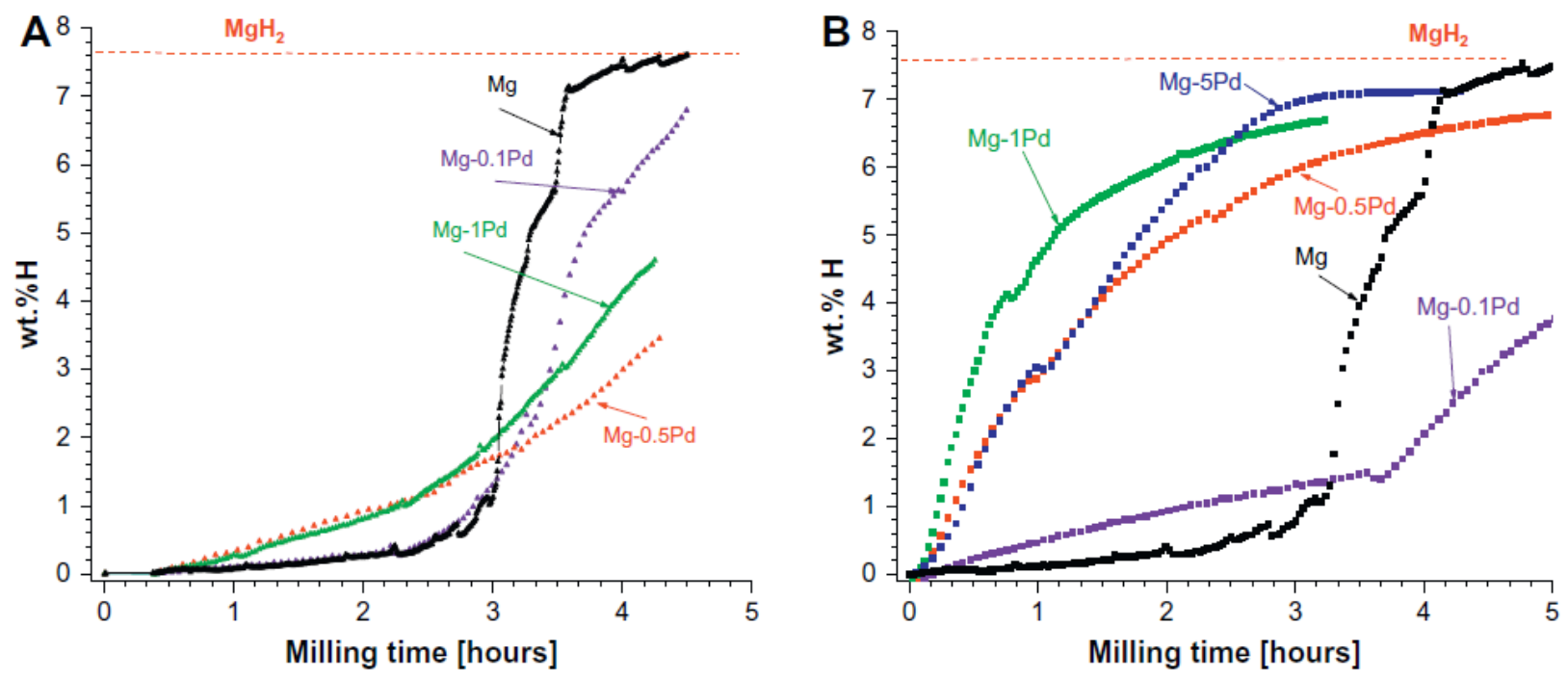

Fig. 1. $\mathrm{H}$ absorption during HRBM of Mg with amorphous (A) and crystalline (B) Pd black.

During refinement, Gaussian profile parameters (GU, GV and GW) were fixed (kept the same as for the $\mathrm{Al}_{2} \mathrm{O}_{3}$ standard), and only two Lorentzian profile parameters were refined, LX (size broadening) and LY (strain broadening). 1 The refinements yielded lattice periods of the constituent phases, as well as estimations of their abundances and crystalline sizes. The latter were calculated using the formula [15]:

$$
D_{V}=\frac{18,000 K \lambda}{\pi X}
$$

where DV is a volume-weighted crystallite size, $\mathrm{K}$ is the Scherrer constant (assumed to be equal to 1), $\mathrm{X}$ is a Lorentzian profile parameter LX.

Dehydrogenation and re-hydrogenation performances of the materials after HRBM were studied using a Sieverts-type volumetric setup. $200 \mathrm{mg}$ of the sample powder was loaded into the reactor which, together with the 
measurement system, was further evacuated to $<10^{-4}$ mbar. Thermal desorption measurements (TDS) were carried out by heating the reactor at a heating rate of $5{ }^{\circ} \mathrm{C} / \mathrm{min}$ from 25 to $460-470{ }^{\circ} \mathrm{C}$ under dynamic vacuum conditions; the vacuum sensor was calibrated on the flow rate of $\mathrm{H}_{2}$ supplied into the measurement system. Further re-hydrogenation was carried out at rv15 bar $\mathrm{H}_{2}$ and $230^{\circ} \mathrm{C}$ for rv4 $\mathrm{h}$ followed by cooling down to room temperature. Two TDS re-hydrogenation cycles were performed for each sample.

\section{Results and discussion}

Table 1 summarises the data on hydrogenation (during HRBM), re-hydrogenation and dehydrogenation performances of the studIed composites. The selected data on $\mathrm{H}$ absorption during HRBM are presented in Fig. 1.

For $\mathrm{Mg}-\mathrm{xPd}$ minor improvements of the performances were observed only when using crystalline Pd black introduced in the amount x P 0:5 wt.\%. The increase of the Pd content above this threshold does not result in a noticeable increase of hydrogenation and re-hydrogenation rates, as well as in a noticeable decrease of TDS peak temperature.

As illustrated by TEM images (Fig. 2), the as-milled powders consist of agglomerates of polycrystalline $\mathrm{MgH}_{2}$ particles, $100-200 \mathrm{~nm}$ in size. Twinning, whose appearance is typical for ball-milled $\mathrm{MgH}_{2}$ [16], was also observed.

Bright- (Fig. 2A and B) and dark-field (Fig. 2C and D) TEM micrographs indicate the presence, in addition to $\mathrm{MgH}_{2}$, of less electron-transparent phase(s) containing noticeable amounts of Pd. The average Pd content in the sample determined by EDS was of 3.43 wt.\% corresponding well to the starting sample composition. Since neither Pd, nor PdH could be detected through XRD refinement (see below), the appearance of the less electron-transparent areas could be accredited to new phase(s) containing both $\mathrm{Mg}$ and $\mathrm{Pd}$ (i.e. $\mathrm{Mg}-\mathrm{Pd}$ intermetallides).

It is seen from the low magnification bright-field image (Fig. 2A) that dark inclusions presenting Pd-rich particles are uniformly distributed in the $\mathrm{MgH}_{2}$ matrix. The inclusions vary in size: few relatively big (50-100 $\mathrm{nm}$; delimited by circle) and majority very small ( $<10 \mathrm{~nm}$; shown by arrows). In the dark field images (Fig. $2 \mathrm{C}$ and $\mathrm{D}$ ) it is visible that a separate phase exists in the $\mathrm{Mg}$ matrix, as evidenced by the areas of bright contrast. This new phase exhibits a basal plane alignment which has long-range arrangement (Fig. 2D; the corresponding region is delimited by a rectangle).

Fig. 3 shows XRD patterns of the as-milled (A) and re-hydrogenated (B) $\mathrm{Mg}-5 \mathrm{Pd}$ (crystalline). Results of refinement of the typical XRD patterns are summarised in Table 2.

The patterns of the as-milled samples (see Fig. 3A as an example) exhibit broad peaks of tetragonal a- c-modifications of $\mathrm{MgH}_{2}$ with lattice periods corresponding well to the

\section{http://repository.uwc.ac.za}


literature data $[17,18]$, and crystallite size of $10-12 \mathrm{~nm}$, with the trend of a slight increase with increasing Pd content in the composite.

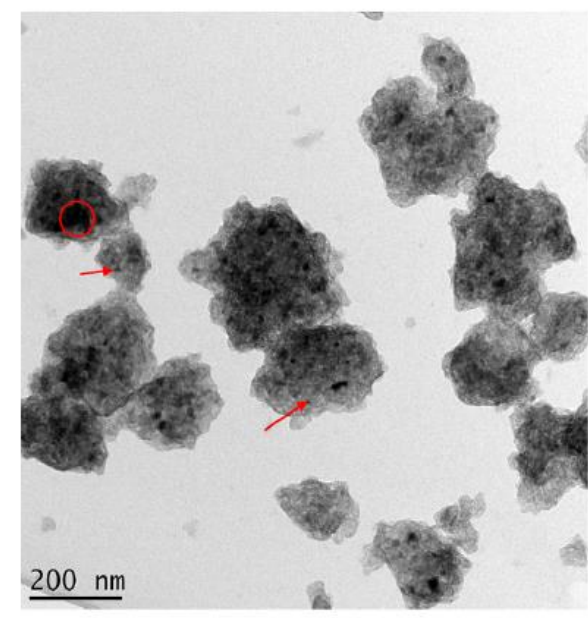

A

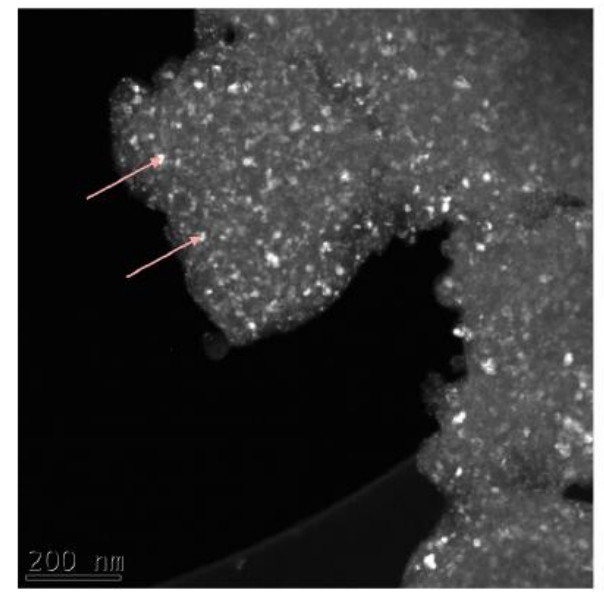

C

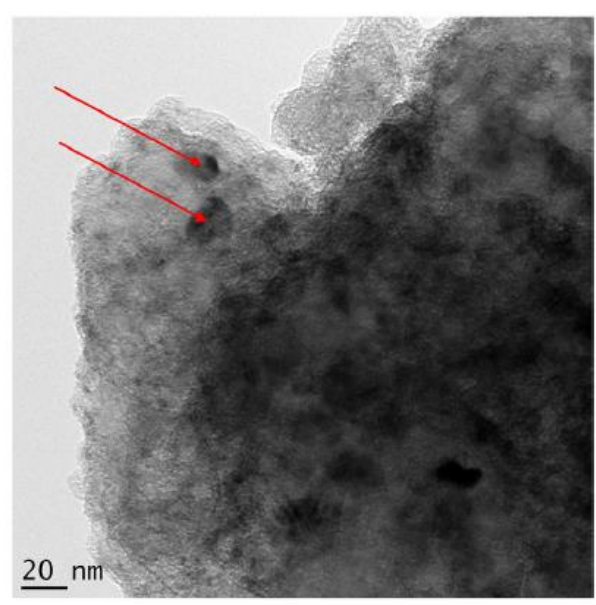

B

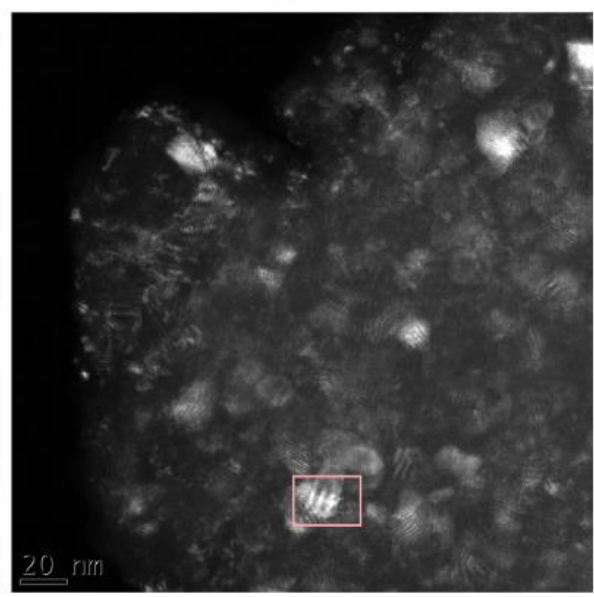

D

Fig. 2. Bright (A and B) and dark (C and D) field TEM micrographs of as-milled sample Mg-5 wt.\% of crystalline Pd black. Circle delimits a typical large particle of Pdcontaining phase, arrows show examples of small Pd-containing particles, and rectangle delimits region of Pd-containing phase exhibiting long-range basal plane alignment.

Palladium and palladium hydride were not observed in the patterns. However, for the samples containing P2 wt.\% of Pd black, the better refinement was obtained assuming presence of a poorly-crystallized MgPd intermetallide (CsCl-type; space group \# 221; $\mathrm{a}=3.12 \AA[19])$, crystallite size below $10 \mathrm{~nm}$. For $\mathrm{Mg}-5 \mathrm{wt} . \% \mathrm{Pd}$, the refinement was further improved assuming the presence of $\mathrm{Mgo.9}_{9} \mathrm{Pd}_{1.1}$ (AuCu-type; space group \# 123; $\mathrm{a}=3.03 \AA, \mathrm{c}=3.42 \AA$ [20]) with quite large crystallites $(75 \mathrm{~nm})$. The estimated abundances and crystallite sizes of Pd-containing phases in $\mathrm{Mg}-5$ wt.\% Pd (Table 2) are in good correspondence with TEM observations (Fig. 2A).

The re-hydrogenated samples (see example in Fig. 3B) contained major phase of a$\mathrm{MgH}_{2}$; abundance $>75 \mathrm{wt}$.\%, and crystallite size about $90 \mathrm{~nm}$. A significant amount (1017 wt.\%) of non-hydrogenated $\mathrm{Mg}$, crystallite size above $100 \mathrm{~nm}$, was observed as well. The patterns of the re-hydrogenated samples containing P2 wt.\% Pd exhibit well- 
resolved peaks belonging to the impurity of Mg6Pd (space group \# 216; $\mathrm{a}=20.108 \AA$ [21]). The most intensive peaks of Mg6Pd are marked by arrows in Fig. 3B. Furthermore, better refinement was obtained assuming additional presence of poorly-crystallized MgPd (Fig. 3A, Table 2), but in lesser amounts than in the as-milled sample. The fitted lattice period of MgPd corresponded well to the literature data [19]. Finally, the XRD patterns of the re-hydrogenated samples exhibited the presence of $\mathrm{MgO}$ formed due to oxidation of the sample.

Our observations allow us to conclude that mechanical alloying of magnesium with palladium takes place already during HRBM. Most probably, this process starts from the formation of $\mathrm{Mg}_{0.9} \mathrm{Pd}_{1.1}$, the most stable intermetallide in $\mathrm{Mg}-\mathrm{Pd}$ system [22], on the surface of $\mathrm{Pd}$ particles. During the milling followed by dehydrogenation/rehydrogenation, due to diffusion of $\mathrm{Mg}$, this phase is enriched with $\mathrm{Mg}$ to form MgPd and, further, Mg6Pd. Similar results were obtained by Roquefere et al. [23] who prepared $\mathrm{Mg}_{6} \mathrm{Pd}$ by $\mathrm{MM}$ of stoichiometric mixture of $\mathrm{Mg}$ and $\mathrm{Pd}$, and Pasquini et al. [24] who observed the formation of $\mathrm{MgPd}, \mathrm{Mg}_{5} \mathrm{Pd}_{2}$ and $\mathrm{Mg}_{3} \mathrm{Pd}$ in the course of PVD of Pd onto Mg nanoparticles.

In summary, the $\mathrm{Mg}-\mathrm{xPd}$ nanocomposites are characterised by modest improvements of their dehydrogenation and re-hydrogenation behaviour as compared to HRBM Mg (Table 1). The reason for that seems to be in the high "metallurgical affinity" between $\mathrm{Mg}$ and Pd forming a wide spectrum of intermetallic compounds [22]. 
Table 2

Characteristics of constituent phases in Mg-Pd composites prepared using crystalline Pd black.

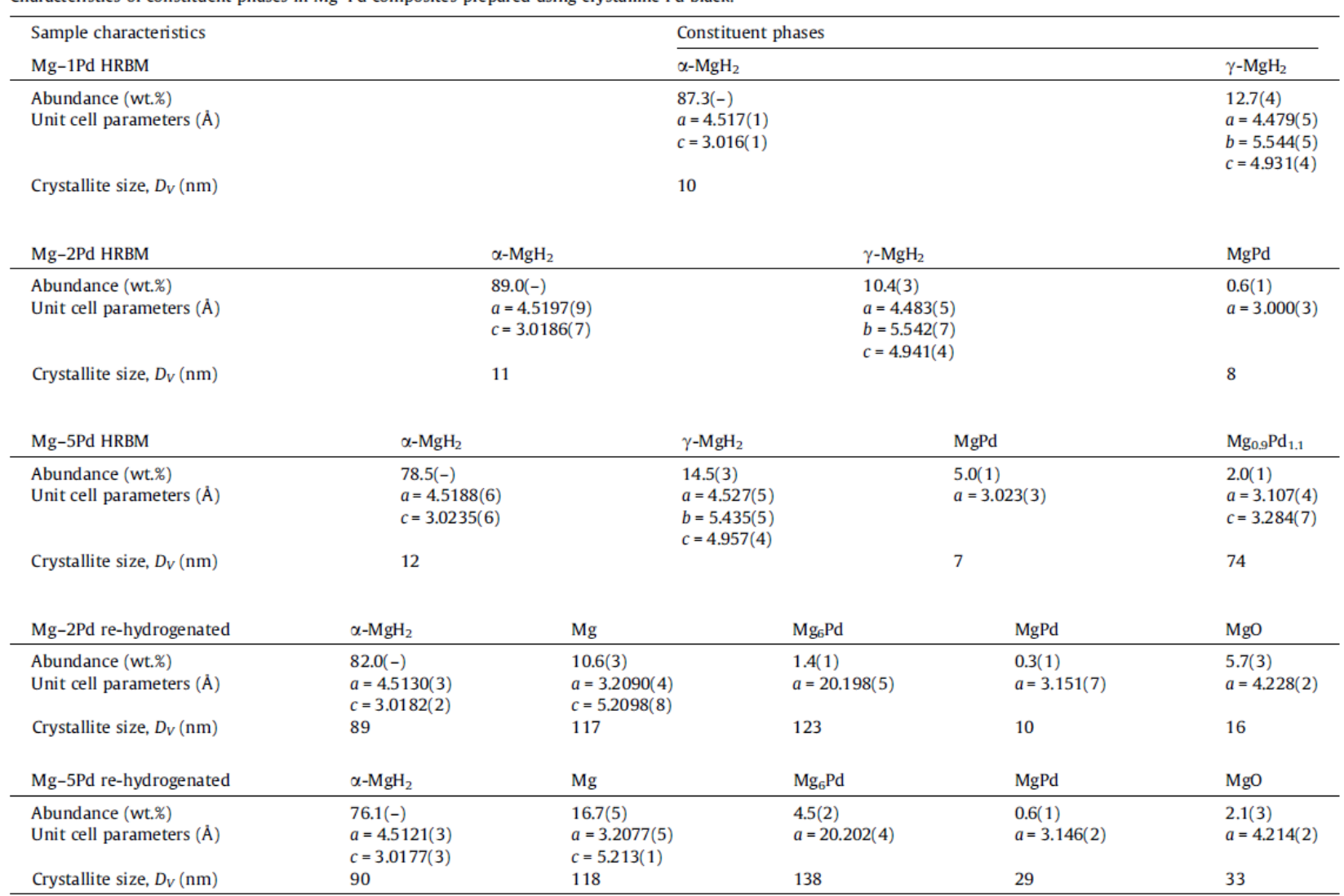
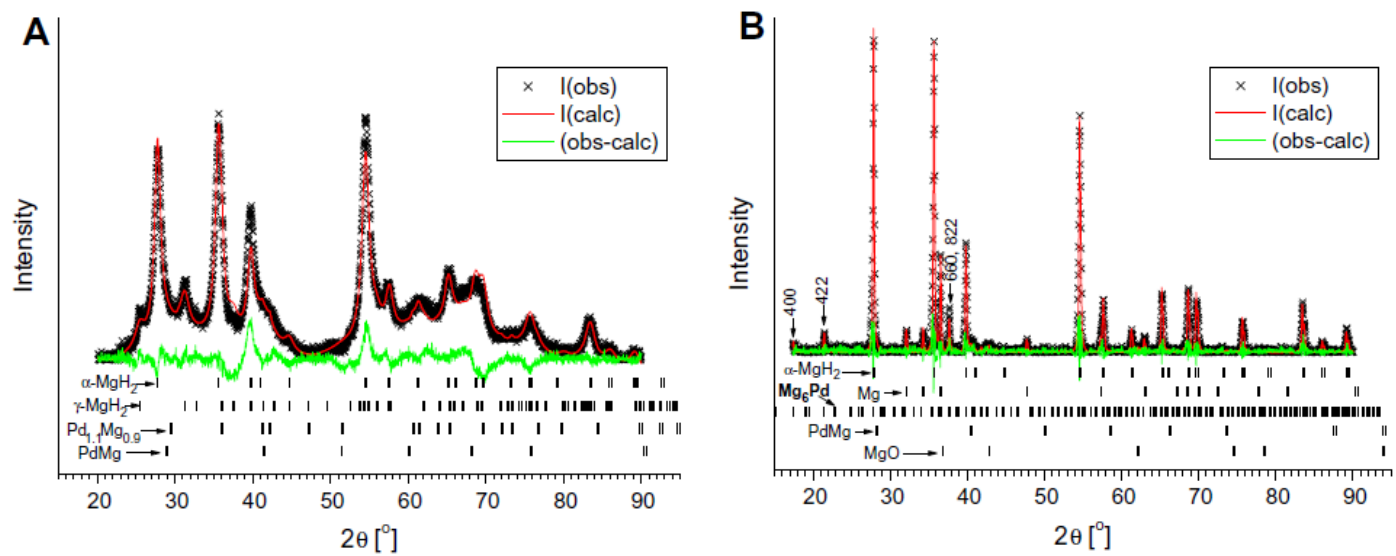

Fig. 3. XRD patterns of as-milled (A) and re-hydrogenated (B) samples Mg-5 wt.\% of crystalline Pd black. The most intensive well-resolved peaks of Mg $\mathrm{g}_{6} \mathrm{Pd}(\mathrm{B})$ are labelled by arrows.

Hydrogenation of $\mathrm{Mg}-\mathrm{Pd}$ intermetallides is quite difficult: so far it was reported about formation of a-solid solution $\mathrm{Pd}_{3} \mathrm{MgH}_{\mathrm{O} .7}$ [25] and ternary hydride $\mathrm{PdMg}_{2} \mathrm{H}$ [26]; reaction of $\mathrm{Mg}_{6} \mathrm{Pd}$ with $\mathrm{H}_{2}$ yielding $\mathrm{Mg}_{3} .65 \mathrm{Pd}$ and $\mathrm{MgH}_{2}$ proceeds very slowly [23]. We suppose that the formation of $\mathrm{Mg}-\mathrm{Pd}$ intermetallides observed in the course of the XRD studies results in the lowering of the catalytic activity of initial Pd particles thus exhibiting the minor (if any) effect of improvement of hydrogen sorption performances of the based nanocomposites. 


\section{Conclusions}

Improvements of hydrogenation kinetics during $\mathrm{HRBM}$ of $\mathrm{Mg}-\mathrm{Pd}$, as compared to HRBM Mg, were observed only for the materials prepared using crystalline Pd black (Po.5 wt.\%). The obtained nanocomposites were characterised by modest improvements of their dehydrogenation and re-hydrogenation performances associated with the formation of $\mathrm{Mg}-\mathrm{Pd}$ intermetallides that results in the lowering of the catalytic activity of initial Pd particles.

\section{Acknowledgements}

This development was funded by Department of Science and Technology of South Africa via HySA Program, Project KP3-So4. ML also thanks National Research Foundation of South Africa (NRF) for the support via Incentive Funding Grant. 


\section{References}

[1] I.P. Jain, C. Lal, A. Jain, Int. J. Hydrogen Energy 35 (2010) 5133-5144.

[2] A. Zaluska, L. Zaluski, J.O. Ström-Olsen, J. Alloys Comp. 288 (1999) 217-225.

[3] G. Liang, J. Huot, S. Boily, A. Van Neste, R. Schulz, J. Alloys Comp. 292 (1999) 247-252.

[4] J. Charbonnier, P. de Rando, D. Fruchart, S. Miraglia, L. Pontonnier, S. Rivoirard, N. Skryabina, P. Vulliet, J. Alloys Comp. 383 (2004) 205-208.

[5] M.Y. Song, S.N. Kwon, H.R. Park, J.L. Bobet, Int. J. Hydrogen Energy 36 (2011) 12932-12938.

[6] J.L. Bobet, B. Chevalier, M.Y. Song, B. Darriet, J. Etourneau, J. Alloys Comp. 336 (2002) 292-296.

[7] M.V. Lototsky, R.V. Denys, V.A. Yartys, Int. J. Energy Res. 33 (2009) 11141125. [8] Y.B. Pan, Y.F. Wu, Q. Li, Int. J. Hydrogen Energy 36 (2011) 1289212901.

[9] N. Mahmoudi, A. Kaflou, A. Simchi, J. Power Sources 196 (2011) 46044608.

[10] A. Krozer, B. Kasemo, J. Phys.: Condens. Matter l (1989) 1533-1538.

[11] J. Dufour, J. Huot, J. Alloys Comp. 439 (2007) L5-L7.

[12] J. Qu, B. Sun, J. Zheng, R. Yang, Y. Wang, X. Li, J. Power Sources 195 (2010) 1190-1194.

[13] A.Ye. Yermakov, N.V. Mushnikov, M.A. Uimin, V.S. Gaviko, A.P. Tankeev, A.V. Skripov, A.V. Soloninin, A.L. Buzlukov, J. Alloys Comp. 425 (2006) 367-372.

[14] M.V. Lototsky, M. Williams, V.A. Yartys, Ye.V. Klochko, V.M. Linkov, J. Alloys Comp. 509 (2011) S555-S561.

[15] A.C. Larson, R.B. Von Dreele, General Structure Analysis System (GSAS), Los Alamos National Laboratory Report LAUR, 86-748, 2004.

[16] M. Danaie, D. Mitlin, J. Alloys Comp. 476 (2009) 590-598.

[17] J.M. Haschke, M.R. Clark, High Temp. Sci. 7 (1975) 152-158.

[18] M. Bortz, B. Bertheville, G. Böttger, K. Yvon, J. Alloys Comp. 287 (1999) L4L6.

[19] H.H. Stadelmaier, W.K. Hardy, Z. Metallk. 52 (1961) 391-396.

[20] P.I. Kripyakevich, E.I. Gladyshevskii, Sov. Phys. Crystallogr. 5 (1960) 552554. translated from Kristallografiya.

[21] S. Samson, Acta Crystallogr., B 28 (1972) 936-945.

[22] A.A. Nayeb Hashemi, J.B. Clark, Mg-Pd (Magnesium-Palladium), in: T.B. Massalski (Ed.), Binary Alloy Phase Diagrams, vol. 3, second ed., Springer, Berlin, 1990, pp. 2535-2536.

[23] J.-G. Roquefere, J. Lang, A. Yonkeu, J. Dufour, J. Huot, Int. J. Hydrogen Energy 36 (2011) 2165-2169.

[24] L. Pasquini, E. Callini, M. Brighi, F. Boscherini, A. Montone, T.R. Jensen, C. Maurizio, M.V. Antisari, E. Bonetti, J. Nanopart. Res. 13 (2011) 5727-5737.

[25] H. Kohlmann, G. Renaudin, K. Yvon, C. Wannek, B. Harbrecht, J. Solid State Chem. 178 (2005) 1292-1300. 
[26] Y. Goto, H. Kakuta, A. Kamegawa, H. Takamura, M. Okada, J. Alloys Comp. 404-406 (2005) 448-452. 